\title{
The quality and effectiveness of Strategic Environmental Assessment (SEA) as a decision-aiding tool for national park expansion-the greater Addo Elephant National Park case study
}

\section{F. RETIEF}

Retief, F. 2006. The quality and effectiveness of Strategic Environmental Assessment (SEA) as a decision-aiding tool for national park expansion - the greater Addo Elephant National Park case study. Koedoe 49(2): 103-122. Pretoria. ISSN 0075-6458.

Internationally South Africa is regarded as a leading developing country in the application of SEA. Research also indicates that the conservation sector within South Africa has been particularly prominent in exploring its application. However, very little empirical research has been conducted to learn from practice and to establish the added value of SEA to strategic decision making. To address this gap in knowledge the paper explores the input quality and output effectiveness of the greater Addo Elephant National Park SEA. The results show that the SEA achieved average to good input quality and output effectiveness performance, respectively. A number of lessons were learned for the application of SEA to future park expansion initiatives. These relate to the timing of the SEA, addressing social impacts, setting of boundaries as well as dealing with scale. The research results concluded that SEA made valuable contributions to decision making and could be considered an important decision-aiding tool for the conservation sector. To take the debate forward and to benchmark best practice it is proposed that further comparative performance evaluation research of multiple SEA case studies within the conservation sector be conducted.

Key words: strategic environmental assessment, quality and effectiveness, performance evaluation, park expansion, conservation sector

F. Retief, Senior lecturer, School of Environmental Sciences and Development, North West University (Potchefstroom campus), Private Bag X6001, Potchefstroom, 2520, South Africa, (ggffpr@puk.ac.za).

\section{Introduction}

South Africa, with its exceptional natural beauty and cultural diversity is sometimes fittingly described as a world in one country and the rainbow nation. Although the country is world renowned for its achievements in the field of conservation and biodiversity management, it is also known for its turbulent political past marred by inequality and social injustice. It is a context where sustainability cannot be considered lightly because it deals with pressing short term survival issues as well as longer term concerns with quality of life. Strategic Environmental Assessment (SEA) was introduced as a tool that could assist with integrating the concept of sustainability into strategic level decision making
(CSIR 1996; DEAT 2000; Rossouw et al. 2000; DEAT 2004b). The introduction of SEA has been on the back of extensive international refinement and wide adoption within developed as well as developing country contexts (Dalal-Clayton \& Sadler 2005; Jones et al. 2005; Schmidt et al. 2005). In terms of developing countries, South Africa has received international acclaim for its homegrown approach to SEA (Therivel \& Partidario 2000; Dalal-Clayton \& Sadler 2005). The extent of SEA practice within the country is also considered exceptional, with 50 SEAs conducted across nine different sectors between 1996 and 2003 (Retief 2005). The three best-represented sectors were planning, conservation and water management. However, very little research has been conducted 
on the quality and effectiveness of SEA within these different sectors.

From a conservation perspective, South Africa is classified by the World Conservation Monitoring Centre as the third most biologically diverse country in the world (World Conservation Monitoring Centre 1992, 2002). However, this status also inevitably complicates the trade-offs that need to be made between the country's pressing development needs and its wealth in biodiversity. Wynberg (2002) tracked the progress in biodiversity conservation in South Africa from the Rio Earth Summit in 1992 to the Johannesburg World Summit on Sustainable Development (WSSD) in 2002 and suggests that a paradigm shift has taken place where biodiversity shifted from the realms of pure conservation synonymous with 'saving the rhino', to encompassing politics, culture and economy. This shift has come about through the democratisation process in South Africa, but also changes in international thinking on resource management. Subsequently, sustainable development is understood as a development approach rather than a biodiversity conservation strategy.

Since the WSSD in 2002, South Africa, in an effort to address the lack of a national strategic framework has promulgated the National Environmental Management Biodiversity Act (NEMBA) 10 of 2004, published a National Biodiversity Strategy and Action Plan as well as a National Spatial Biodiversity Assessment (DEAT 2004a). Moreover, in line with international thinking (Kolhoff \& Slootweg 2005; Treweek et al. 2005), specific biodiversity-focused approaches to planning, such as the bioregional approach, have emerged more strongly (NBI 2002). An example is the Cape Action Plan for the Environment (CAPE) that explicitly incorporated SEA elements (Lochner et al. 2003). However, due to continued institutional and legal fragmentation, as well as until recently the lack of a national sustainability strategy, little progress has been made to incorporate biodiversity issues into mainstream decision making (Rossouw \& Wiseman 2004; Glazewski 2005). As Wynberg (2002) states: “..., biodiversity considerations at the strategic planning level remain marginalised and narrow, and sorely neglected within existing plans. ... Strategic Environmental Assessment allows issues of biodiversity to be more strongly integrated into the formulation of policies, plans and programmes."

Thus, although the exact role and potential added value of SEA to conservation and biodiversity decision making is still unclear, and has not entered formal debate, SEA already seems to have started to make important contributions (Brownlie et al. 2005). This paper explores the quality and effectiveness of SEA as a tool to inform strategic decision making related to conservation. The aim is to highlight the added-value of SEA but also to gain experience in tailoring SEA as a tool to assist initiatives involving the establishment of new and extension of existing conservation areas within South Africa. The complexities associated with SEA performance evaluation required a case study research approach. For this reason, a specific high-profile SEA case study was identified, namely the greater Addo Elephant National Park (gAENP) SEA.

\section{Case study—greater Addo Elephant}

\section{National Park}

The Addo Elephant National Park (AENP) had its humble beginnings in 1931 when it was proclaimed to protect the last dwindling population of Eastern Cape elephants. Since then, the park has been expanded from its original 2200 ha to over 120000 ha in 2004, and potentially over 400000 ha in future (Fig. 1). But the AENP was not the only conservation area established in the region. Several other provincial reserves and private reserves were established, as well as three conservancies and two heritage sites. The integration of these different conservation areas was desirable, since from a biodiversity management perspective, 'single large' is better than 'several small'. In 1997, Kerley \& Boshoff (1997) completed an awardwinning proposal that set out the framework 
for a greater AENP that would integrate and extend these existing conservation areas. The challenge for the park was accepted by South African National Parks (SANParks) and set the scene for one of the most ambitious, and potentially significant, contributions to biodiversity conservation in Africa. The new enlarged park would be the third largest national park in South Africa and cover six of the seven South African biomes.

The implementation of such an ambitious endeavour would, however, require extensive funding, which could not be accessed fully nationally. Due to the potential international contribution the project could make to conservation it was feasible to approach international funding agencies (the overall gAENP expansion initiative was referred to as a 'project' which might cause some confusion since SEA normally relates to policy, plan and programme (PPP) levels of decision making). Ultimately the Global Environment Facility (GEF) provided a grant, administered through the World Bank (WB), to conduct a series of specialist studies to form the basis for a full project proposal for further funding. The WB has a number of safeguard policies, which had to be adhered to if further funding was to be secured. In 2002, a SEA was commissioned as a requirement in accordance with WB safeguard policy requirements and aimed to consolidate all the specialist information in a manner that would facilitate sound strategic planning and decision making. The lead agent of the SEA was SANParks who appointed Coastal and Environmental Services (CES) as the consultancy to carry out the SEA in line with the 2000 South African SEA guidelines (DEAT 2000; CES 2002).

The entire area specifically considered as part of the SEA for the gAENP is referred to as the 'planning domain'. It includes a

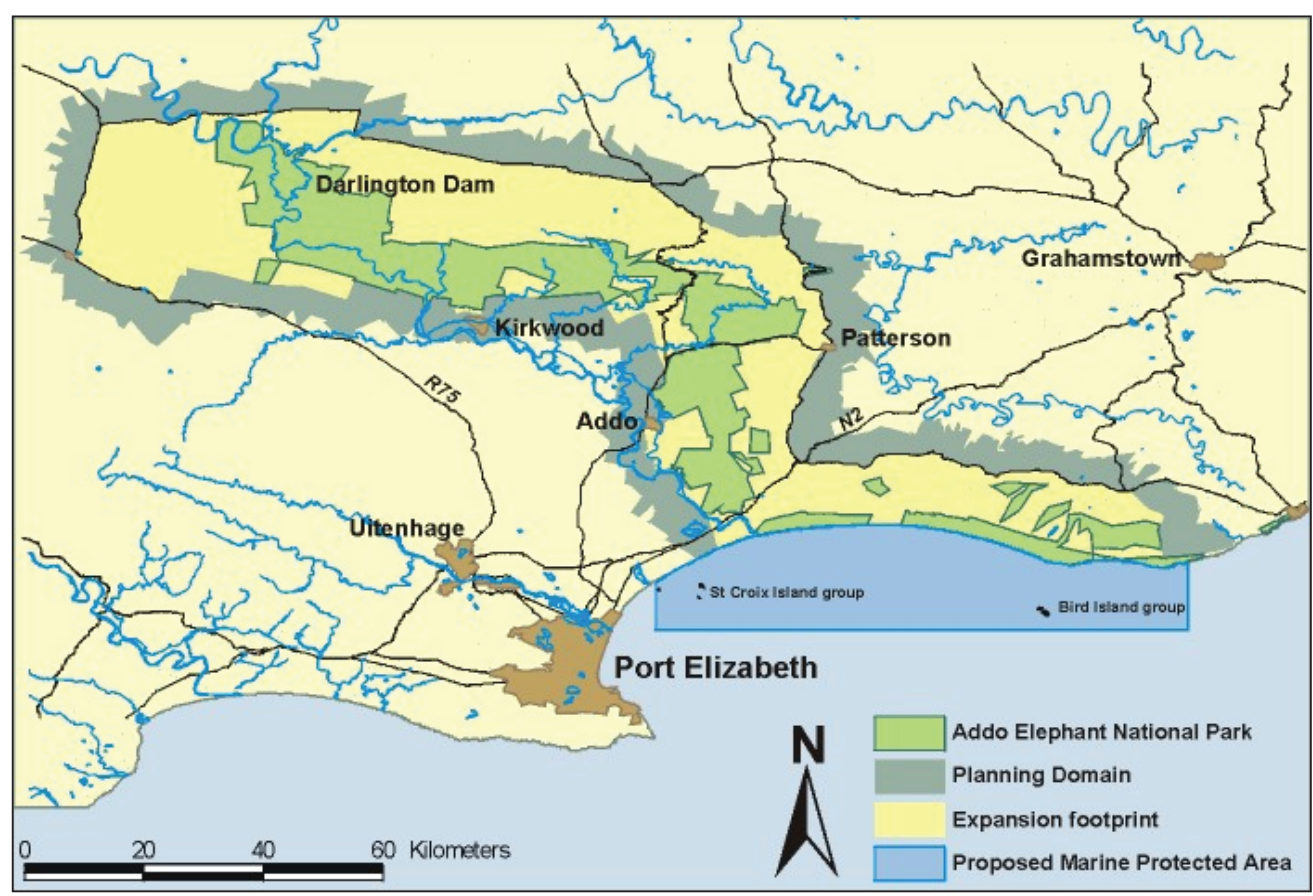

Fig. 1. Extent of the gAENP planning domain (CES 2002) 
terrestrial area of approximately 340000 ha (around which a $5 \mathrm{~km}$ buffer is included) and a marine area of approximately 100000 ha inclusive of the St Croix and Bird Island groups (Fig. 1). The criteria used to determine the boundaries of the planning domain related to the potential of the park to achieve certain conservation and development goals in line with South Africa's development policies and strategies on the environment (Kerley \& Boshoff 1997; CES 2002). These goals relate to the significance of the biodiversity assets as well as the need to facilitate compatible development, such as tourism to address social and economic needs typical of the underdeveloped rural areas of the Eastern Cape, South Africa's poorest province. Examples of the biophysical assets for the area covered by the park include:

- Terrestrial Environment (CSIR 2002)The terrestrial environment covers six biomes of which the Thicket Biome is best represented, covering $69 \%$ of the planning domain. The others are Forest (10\%), Nama Karoo (7\%), Fynbos (5\%), Grassland (5\%) and Savanna (4\%). The Alexandria forest is unique and endemic to the Eastern Cape while Fynbos is renowned for its diversity of floral species. The most conspicuous faunal species are the Addo elephant (Loxondonta africana) and the black rhinoceros (Diceros bicornis bicornis and D.b.michaeli). Other less visible but extremely significant species include the endemic dune grasshopper (Arctylos hirsutus) and hairy-footed gerbil (Gerbillurus paeba exilis).

- Freshwater environment (CSIR 2001b)The planning domain includes nine different types of water bodies having a complement of biotopes, namely: perennial and seasonal rivers; episodic rivers; ephemeral rivers; permanent and semipermanent vleis; seasonal vleis; springs and seeps; episodic endorheic pans; forest swamps and marches. A number of threatened faunal species rely on these bodies for survival such as the redfin minnow (Barbus afer).
- Marine environment (CSIR 2001a)The proposed marine protected area (MPA) is of national and international significance. Due to its location, the fish fauna comprises species found on both the east and west coasts of South Africa, many of which are endemic. It is also known for its population of great white shark (Carcharadon carcharias) and 9 species of whale, dolphin and seal are relatively common. The two island groups accommodate a number of bird species of conservation significance such as the African Penguin (Spheniscus demersus) and Roseate Tern (Sterna dougallii), South Africa's most threatened marine bird. Finally the Alexandria coastal dune field is regarded as the largest and least degraded coastal dune field in South Africa.

In light of these bio-physical features the area also presents significant social and development challenges, such as:

- Land ownership and acquisition (Connor 2002; Wren \& Msutu 2002)-Sensitivity surrounding the issue of land ownership presented a particular challenge for the expansion of the park. The majority of farm owners and farm workers have a long-term occupancy in the region, which made the land ownership issue even more contentious. The process used for the acquisition of land was criticised and the possibility of expropriation created negative perceptions. The management scenarios for the park had to consider innovative solutions to accommodate conservation on private land such as contractual agreement initiatives. It also led to the formulation of a Land Acquisition Policy.

- Employment (Antrobus 2002; Connor 2002) - The gAENP project had to show that it would contribute to economic development and employment within the planning domain. Analysis of existing employment patterns related to the different land uses was required to make such estimates. It concluded that conservation combined with tourism should be able to create more employment than existing agricultural land uses, except for dairy farming. Also, ways 
of retraining and redeployment of existing labourers had to be achieved within the requirements of the WB safeguard policies prohibiting any form of involuntary resettlement.

\section{Methods}

Due to the substantial difficulties experienced with SEA performance evaluation (Sadler 2004; Partidario \& Arts 2005), and specifically in dealing with effectiveness (Therivel \& Minas 2002; Cashmore et al. 2004; Owens et al. 2004) no international methodological blue print exists. The performance evaluation methodology for the research was based on the quality and effectiveness SEA review protocol designed by Retief (2005). It was based on national as well as international SEA literature, which provided the basis for the development of a conceptual framework and the identification of existing performance criteria for SEA quality and effectiveness. In line with international literature, the protocol distinguishes between input quality at the level of application and output effectiveness at the level of implementation (Sadler 1996; Lawrence 1997; Thissen 2000a). Furthermore, the protocol distinguishes between three SEA input quality components, namely: process, methodology and documentation. In terms of output effectiveness, two components were identified namely direct and indirect outputs. Direct outputs are understood to relate to the objectives of SEA, which include aspects such as changes to decisions, improvement in the environmental quality and changes to the contents of plans or programmes. Indirect outputs are more difficult to measure and include outputs such as changes in attitudes towards the environment, improved awareness, changes in institutional arrangements and departmental traditions.

To provide some form of measurement, indicators were developed. The use of the term indicators was preferred to criteria because indicators suggest that they are indicative, whereas criteria imply precision not always achievable due to the complex nature of SEA (Todd 2001; Retief 2005). The methodology for the design of key performance areas (KPAs) and key performance indicators (KPIs) was based on the agreed notion that overarching context specific SEA principles and objectives should form the basis for the application of SEA (Marsden 1998; Rossouw et al. 2000; Thissen 2000b; Verheem \& Tonk 2000). Examples of such SEA principles have been designed for SEA internationally (IAIA 2002), and also for South Africa specifically (DEAT 2000). Ultimately, 14 KPAs and 48 KPIs were identified for quality review of SEA. It was based on the understanding that SEA involves a context-specific, sustainability- led, participative, pro-active and efficient process. This requires different SEA methodologies during screening, situation analysis, scoping, environmental assessment and monitoring, and review phases. The results of these need to be documented and communicated to decision makers and interested and affected parties (IAPs). In terms of effectiveness, four KPAs and nine KPIs were developed. Table 1 provides a summary of the KPAs and KPIs for quality and effectiveness and their relation to SEA principles and objectives.

To deal with the qualitative and subjective nature of the conformance measurement only three scales were used namely, conformance, partial conformance and non-conformance. The level of conformance was determined through in-depth analysis of the SEA documentation as well as interviews with selected key role players. The basic assumption is that conformance to more indicators implies better quality and/or effectiveness performance (for a more detailed description of the protocol see Retief (2005)). However, the literature warns against just adding up different variable scores as with a quantitative survey approach (Miles \& Huberman 1994; Yin 2003). This would destroy the local web of causality and result only in a smoothed down set of generalisations. As reflected in the following sections the research ultimately aimed to tell a story rather than produce a quantitative performance score.

\section{Results and discussion}

Table 2 provides a summary of the overall review results. The input quality results show that the SEA failed to conform to 13 indicators, partly conformed to 20 and conformed to 15 of the 48 indicators. The larger number of partly conformed and conformed indicators suggests an average to good quality performance. On the other hand, the output effectiveness performance shows conformance or partial conformance to all except one of the indicators (the status of two of the indicators could not be established). This also suggests an average to good effectiveness performance.

Although it is not possible at this stage to identify specific linkages between input quality and output effectiveness it can be concluded that the input quality does seem to be reflected in the output effectiveness with what could be considered average to good performance on both sides. 
Table 1

Summary of linkages between SEA principles, objectives, KPAs and KPIS developed for South Africa (Retief 2005)

\begin{tabular}{|c|c|c|c|}
\hline SEA principles & SEA objectives & KPAs & KPIs \\
\hline $\begin{array}{l}\text { "Basic building blocks } \\
\text { for the context specific } \\
\text { perspectives on SEA in } \\
\text { South Africa" }\end{array}$ & $\begin{array}{c}\text { "Indication of } \\
\text { what needs to be } \\
\text { achieved" }\end{array}$ & $\begin{array}{l}\text { "Theme } \\
\text { related to } \\
\text { princi- } \\
\text { ples" }\end{array}$ & $\begin{array}{l}\text { "Questions that provide an indication if SEA } \\
\text { objectives were achieved" }\end{array}$ \\
\hline $\begin{array}{c}\text { (adapted from DEAT } \\
2000)\end{array}$ & $\begin{array}{l}\text { (adapted from } \\
\text { DEAT 2000) }\end{array}$ & & \\
\hline $\begin{array}{l}\text { Key process } \\
\text { principles }\end{array}$ & $\begin{array}{c}\text { Key process } \\
\text { objectives }\end{array}$ & $\begin{array}{l}\text { Process } \\
\text { KPAs }\end{array}$ & Process KPIs \\
\hline
\end{tabular}

There is not one SEA process to be used in all contexts. This requires a SEA process to be flexible and adaptable, in order to integrate with the decision making context.

Development must be socially, environmentally and economically sustainable. SEA provides a practical means of integrating the concept of sustainability into plan and programme formulation.

Public participation forms an integral part of SEA because SEA puts people and their needs at the forefront of its concern.
- To integrate the SEA with the decision making context.

- To avoid the duplication of processes.
Context specific

KPI 1.1: Was the SEA fully integrated with the plan or programme formulation process, from conceptualisation to implementation?

KPI 1.2: Did the SEA make provision for tiering with project EIA?

KPI 1.3: Did the SEA formulate actor and process configurations?

Sustainabilityled the concept of sustainability into plan and programme level decision making.

- To facilitate the development of local definitions and understandings of sustainability.
- To inform and involve IAPs throughout the SEA process.

- To incorporate public inputs and concerns into decision making processes.

- To facilitate information sharing.
Participative

KPI 3.1: Was a formal public participation process followed, which informed and involved the IAPs throughout the SEA process?

KPI 3.2: Were the IAPs satisfied with the public participation process?

KPI 3.3: Did the SEA explicitly address public inputs and concerns?

KPI 3.4: Were all key state departments and other governing bodies consulted during the SEA? 
Table 1 (continued)

SEA provides a means of influencing decision making throughout its life cycle, from conceptualisation to implementation in an incremental and iterative way while facilitating the concepts of pre-caution and continuous improvement.

The benefits of implementing SEA exceed the costs. SEA adds value to existing decision making by focusing on key strategic environmental issues.
- To ensure that the SEA is implemented early enough to influence decision making.

- To facilitate continual improvement.
Proactive
KPI 4.1: Did the SEA ensure availability of the assessment results early enough to influence the decision making process?

KPI 4.2: Was commitment confirmed to ensure that the results of the SEA be considered in future decisionmaking?

Efficient KPI 5.1: Did the SEA provide sufficient information for decision-making according to the relevant decisionmakers?

KPI 5.2: Were sufficient resources and time allocated to conduct the SEA according to the relevant SEA role players?

KPI 5.3: Did the SEA focus on key significant strategic issues? the key environmental issues.

- To optimise the use of time and resources.

- To focus deci-

\section{Methodology KPIs}

Method-
ology KPAs

\begin{tabular}{|c|c|c|c|}
\hline $\begin{array}{c}\text { Key } \\
\text { methodology } \\
\text { principles }\end{array}$ & $\begin{array}{c}\text { Key } \\
\text { methodology } \\
\text { objectives }\end{array}$ & $\begin{array}{l}\text { Method- } \\
\text { ology } \\
\text { KPAs }\end{array}$ & Methodology KPIs \\
\hline
\end{tabular}

SEA has to justify why it needs to be applied and what it aims to achieve.

SEA determines the opportunities and constraints that the environment places on development.
- To justify the need for the SEA.

- To clearly define project objectives of the SEA.

- To provide sufficient information on environmental attributes to identify opportunities and constraints.
Screening

KPI 6.1: Was a formal screening method or criteria applied?

KPI 6.2: Was the need for the SEA clearly defined?

KPI 6.3: Was the purpose and/or objectives of the SEA clearly defined that could serve as reference for effectiveness review?
Situation analysis
KPI 7.1: Was a resource inventory prepared which describes the social, economic and biophysical aspects in the area at the appropriate scale and level of detail?

KPI 7.2: Was the state of the environment (including economic, social and bio-physical) determined against set objectives, criteria or indicators?

KPI 7.3: Were environmental opportunities and constraints identified by means of a justified methodology? 
Table 1 (continued)

SEA identifies the most significant key strategic environmental issues.
- To ensure that key strategic environmental issues are identified.
Scoping

KPI 8.

KPI 8.2: Did scoping ass

KPI 8.2: Did scoping assist in defining the scope and extent of the SEA?

KPI 8.3: Did the scoping method(s) focus the SEA on key significant strategic issues?

KPI 8.4: Were public inputs considered during scoping?

SEA determines the implications of strategic decisions on the environment.
- To ensure that environmental implications of strategic decisions are considered.
SEA aims for continuous improvement, which relies on monitoring and review mechanisms.
- To ensure that the SEA is reviewed and the implementation of proposals monitored.
Environmental assessment

Monitoring and review

KPI 10.2: Has the SEA been independently reviewed?

KPI 10.3: Has environmental monitoring been conducted?

\begin{tabular}{|c|c|}
\hline $\begin{array}{c}\text { Key } \\
\text { documentation } \\
\text { principles }\end{array}$ & $\begin{array}{c}\text { Key } \\
\text { documentation } \\
\text { objectives }\end{array}$ \\
\hline $\begin{array}{l}\text { Information should be } \\
\text { documented in a sound } \\
\text { and justifiable manner. }\end{array}$ & $\begin{array}{l}\text { - To provide } \\
\text { sound and } \\
\text { justifiable } \\
\text { information, } \\
\text { which allows for } \\
\text { verification of } \\
\text { results. } \\
\text { - To contribute to } \\
\text { existing envi- } \\
\text { ronmental data } \\
\text { and information. }\end{array}$ \\
\hline
\end{tabular}

\section{Docu- \\ menta- \\ tion \\ KPAs}

Descrip- KPI 11.1: Were the purpose and objectives tion of of the SEA described in the docuContext

KPI 11.2: Was the decision making contexts and linkages with other decision making processes described?

KPI 11.3: Was a description provided of the SEA process followed?

KPI 11.4: Were those involved in consultation and participation indicated? 
Table 1 (continued)

Descrip- KPI 12.1: Was a description provided of the tion of current state of the environment the state of the environ(either as a separate volume or

ment

KPI 12.2: Was the state of the environment described against clear thresholds and/or limits of acceptable change in a way that highlights relative significance?

Description of assessment methodology and results

SEA should be documented in a manner that ensures effective communication of results in order to optimise the possibility of it influencing decision making.
- To communicate the results of the SEA to decision makers.

- To communicate the results of the SEA to IAPs.
Communication of results

KPI 14.2: Were the specialist reports well referenced and integrated in a way that promotes a self-contained document?

KPI 14.3: Was a non-technical summary provided of the main results and conclusions?

KPI 14.4: Were the inputs received from IAPs incorporated in the report?

\begin{tabular}{|c|c|c|c|c|}
\hline $\begin{array}{c}\text { Key } \\
\text { direct outputs } \\
\text { principles }\end{array}$ & $\begin{array}{c}\text { Key } \\
\text { direct outputs } \\
\text { objectives }\end{array}$ & $\begin{array}{l}\text { Direct } \\
\text { outputs } \\
\text { KPAs }\end{array}$ & & Direct outputs KPIs \\
\hline \multirow[t]{2}{*}{$\begin{array}{l}\text { SEA influences the } \\
\text { contents of plans and } \\
\text { programmes. }\end{array}$} & \multirow{2}{*}{$\begin{array}{l}\text { To influence } \\
\text { the contents } \\
\text { of plans and } \\
\text { programmes. }\end{array}$} & \multirow{2}{*}{$\begin{array}{l}\text { Policies, } \\
\text { plans } \\
\text { and pro- } \\
\text { grammes }\end{array}$} & KPI 15.1: & $\begin{array}{l}\text { Were any plans or programmes } \\
\text { amended based on the proposals } \\
\text { of the SEA? }\end{array}$ \\
\hline & & & KPI 15.2: & $\begin{array}{l}\text { Did the SEA facilitate the incor- } \\
\text { poration of sustainability objec- } \\
\text { tives into relevant plans or pro- } \\
\text { grammes? }\end{array}$ \\
\hline
\end{tabular}


Table 1 (continued)

\begin{tabular}{|c|c|c|c|c|}
\hline \multirow[t]{2}{*}{$\begin{array}{l}\text { SEA facilitates the } \\
\text { achievement of sustain- } \\
\text { ability objectives }\end{array}$} & $\begin{array}{l}\text { - To achieve the } \\
\text { SEA project } \\
\text { objectives. }\end{array}$ & $\begin{array}{l}\text { SEA } \\
\text { objec- } \\
\text { tives }\end{array}$ & KPI 16.1: & $\begin{array}{l}\text { Were the SEA project objectives } \\
\text { achieved (as described in the } \\
\text { TOR)? }\end{array}$ \\
\hline & $\begin{array}{l}\text { - To achieve } \\
\text { the SEA } \\
\text { sustainability / } \\
\text { environmental } \\
\text { objectives. }\end{array}$ & & KPI 16.2: & $\begin{array}{l}\text { Were the sustainability / envi- } \\
\text { ronmental objectives achieved (as } \\
\text { might be described in relation to } \\
\text { the vision)? }\end{array}$ \\
\hline \multirow[t]{3}{*}{$\begin{array}{l}\text { SEA influences deci- } \\
\text { sion making }\end{array}$} & $\begin{array}{l}\text { To influence } \\
\text { decision mak- } \\
\text { ing. }\end{array}$ & $\begin{array}{l}\text { Decision } \\
\text { making }\end{array}$ & KPI 17.1: & $\begin{array}{l}\text { Were decisions changed or amend- } \\
\text { ed based on the outcomes and } \\
\text { proposals of the SEA? }\end{array}$ \\
\hline & & & KPI 17.2: & $\begin{array}{l}\text { Was the SEA implemented as a } \\
\text { decision-support guideline for } \\
\text { future development proposals? }\end{array}$ \\
\hline & & & KPI 17.3: & $\begin{array}{l}\text { Did the SEA inform/guide sub- } \\
\text { sequent project level decision } \\
\text { making (such as EIA or water } \\
\text { licensing)? }\end{array}$ \\
\hline \multirow[t]{2}{*}{$\begin{array}{l}\text { SEA improves environ- } \\
\text { mental quality }\end{array}$} & $\begin{array}{l}\text { - To improve } \\
\text { environmental } \\
\text { quality }\end{array}$ & $\begin{array}{l}\text { Environ- } \\
\text { mental } \\
\text { quality / } \\
\text { sustain- } \\
\text { ability }\end{array}$ & KPI 18.1: & $\begin{array}{l}\text { Were changes to the environment } \\
\text { observed since the completion of } \\
\text { the SEA process, which could be } \\
\text { attributed to the influence of the } \\
\text { SEA? }\end{array}$ \\
\hline & & & KPI 18.2: & $\begin{array}{l}\text { Did the SEA accurately identify } \\
\text { the key significant strategic envi- } \\
\text { ronmental issues? }\end{array}$ \\
\hline
\end{tabular}

Interpretation of overall results:

Poor: Failure to conform to large majority of indicators.

Average to poor: Failure to conform, and/or partial conformance, to the majority of indicators.

Average: Partial conformance to the majority of indicators, or an even spread in performance.

Average to good: Partial, and/or conformance, to the majority of indicators.

Good: Conformance to large majority of indicators.

\section{Input quality components}

\section{- $\quad$ SEA process component}

The review results show that the SEA failed to conform to four, partly conformed to seven, and conformed to five of the 16 indicators. This section describes the SEA process quality with specific reference to KPIs 1.1, 2.4, 3.1, 4.1, 4.2 and 5.2 (Table 2).
Tracing the origins of the SEA through documentation and interviews revealed that considerable work on the conceptualisation of the project had already been completed by the time the SEA was initiated (Kerley \& Boshoff 1997) (KPI 4.1). Importantly, this included a public participation process where, during a public workshop on $23 \mathrm{Feb}-$ ruary 1999, consensus was reached and a 
Table 2

Overall performance evaluation results: SEA for the gAENP

\begin{tabular}{|c|c|c|c|c|c|c|c|c|}
\hline & & KPAs & & & & PI resi & & \\
\hline & & Context specific & 1 & 㟥 1.1 & 1.2 & 1.3 & & \\
\hline & & Sustainability led & 2 & 2.1 & 2.2 & 2.3 & & \\
\hline & ల్ర & Participative & 3 & 3.1 & 3.2 & 3.3 & 3.4 & \\
\hline & & Pro-active & 4 & 41 & 4.2 & & & \\
\hline & & Efficient & 5 & 5.1 & 5.2 & 5.3 & & \\
\hline & & Screening & 6 & 6.1 & 6.2 & 6.3 & & \\
\hline : & ठ이 & Situation analysis & 7 & 7.1 & & 7.3 & & \\
\hline 言 & 융 & Scoping & 8 & 8.1 & 8.2 & 8.3 & 8.4 & \\
\hline & $\sum$ & Environmental assessment & 9 & 9.1 & 9.2 & 9.3 & 9.4 & \\
\hline & & Monitoring and review & 10 & & 10.2 & 10.3 & & \\
\hline & & Description of context & 11 & 11.1 & 11.2 & & 11.4 & \\
\hline & : & $\begin{array}{l}\text { Description of state of the } \\
\text { environment }\end{array}$ & 12 & 12.1 & 12.2 & & & \\
\hline & 节 & $\begin{array}{l}\text { Description of assessment } \\
\text { methodology and results }\end{array}$ & 13 & 17 & 13.2 & 13.3 & 13.4 & 13.5 \\
\hline & & Communication of results & 14 & & 14.2 & 14.3 & 14.4 & \\
\hline 证 & & Plans and Programmes & 15 & 15.1 & 15.2 & & & \\
\hline : & 莕 & SEA objectives & 16 & 16.1 & 6.2 & & & \\
\hline $\begin{array}{l}\stackrel{ \pm}{ \pm} \\
\equiv\end{array}$ & $\begin{array}{l}\breve{U} \\
. \\
.\end{array}$ & Decision making & 17 & 17.1 & 17.2 & 17.3 & & \\
\hline$\tilde{0}$ & & Environmental quality & 18 & 18.1 & 18.2 & & & \\
\hline
\end{tabular}

Non-conformance

Partial Conformance

Conformance
Status could not be established

Indicators with a particular relevance to this case study 
unanimous declaration passed in support of the gAENP initiative (TERU 1999). Thereby a real sense of optimism and passion was generated amongst SANParks to realise the vision and objectives formulated for the gAENP initiative.

Based on this initial project conceptualisation phase, SANParks realised that the project would need to comply with EIA legislation because of the change in land use from agriculture to conservation and also expansion of existing services infrastructure such as roads. But, due to the geographic scale and extent of the project, DEAT considered EIA to be unsuitable and advised SANParks that a SEA be conducted instead (Knight 2004 pers. comm.). The consultant remarked that at that stage "SEA was seen as the panacea for all environmental problems" and there did not seem to be clarity on SEA, "Anything not called EIA was considered SEA" (Avis 2004 pers. comm.).

Outcomes of the interviews suggest that the SEA did not include a specific screening phase and was initiated largely based on the limitations of EIA to deal with the particular scale rather than a clear understanding of SEA and what it could deliver.

In view of the timing of the SEA, it is not surprising that one of the major shortcomings was its lack of integration with the conceptualisation phase (KPI 1.1), which resulted in the SEA being unable to influence the original gAENP vision and primary objectives. The terms of reference (TOR), prepared mainly by SANParks, also did not task the SEA to revisit the vision and primary objectives (CES 2002), which the consultant highlighted as a key weakness of the SEA (Avis 2004 pers. comm.). Additionally the public did not understand what the purpose of the SEA would be if it did not have the mandate to question or influence the primary project objectives (Wren \& Msutu 2002). This jeopardised the SEA and risked that it "... be reduced to a validation exercise for a pre-supposed vision and objectives" (Wren 2004 pers. comm.)
From a sustainability perspective one got the impression that there were so-called green and brown lobbies (KPI 2.4). The green lobby seemed to be represented by the proponent and those responsible for conservation planning and the brown lobby by those responsible for the social and economic specialist studies. It was unanimously expressed by those involved in the SEA (including SANParks) that during the early stages of the SEA “The conservation planners did not fully appreciate the social aspects and their constraints to the expansion of the park" (Knight 2004 pers. comm.)

The irony is that, due to its very nature, the gAENP initiative (which involves the expansion of a conservation area and rehabilitation of farm land) would not present any negative biophysical impacts, and the main contribution of the SEA turned out to be towards the social aspects. The perception from IAPs was that SANParks did not anticipate, nor were they sensitive to, the social implications of the park expansion. The biggest social issue was the re-employment of retrenched farm workers (Connor 2002; Wren \& Msutu 2002). The title deeds of many farms stipulated a vacancy clause, which requires the farm to be vacant on transfer from the farmer to SANParks. This implied eviction of the workforce. In light of the long-term residency (spanning generations) many farm workers would not adapt easily to any other way of life. Low levels of education also limit their future employment prospects. It was argued by land owners that SANParks should at least be partly responsible for the livelihoods of these rural communities, especially where expropriation was involved (Connor 2002). To underline the negative perceptions comments were made by some IAPs that "Coega [controversial industrial development in the area] would never have gotten away with the same approach to social issues that the Addo project did" and that, "If it were not for the World Bank safeguard policies on resettlement the social issues would never have been addressed" (Anonymous pers. comm.) 
Due to the (largely unanticipated) significant social issues related to the expansion of the park, the public participation process turned out to be a vitally important contribution to the SEA process (KPI 3.1). Probably the biggest problem for the legitimacy and credibility of the participation process was the continuation of land purchase by SANParks while the SEA process was being conducted (Wren 2004 pers. comm.). The consultants objected to this (Avis 2004 pers. comm.). It was only reasonable and understandable that certain sectors of the public interpreted this as confirmation that the SEA was only a window dressing exercise and that the project was going ahead despite their inputs. In certain areas people withdrew and distanced themselves totally from the process because of this (Wren \& Msutu 2002). However, SANParks argued that they have been purchasing land on a continuous basis since the establishment of the park in the 1930s. Also, the rural areas presented a particular challenge for the participation process where the high profile of the gAENP initiative generated various rumours among the farming community that caused uncertainty and distrust, which included amongst others, expropriation threats. Many farmers have been farming the land for generations and were unwilling to become involved. In this regard farm workers proved even more difficult to liase with since they were isolated on farms and were not organised into representative bodies such as trade unions (Wren \& Msutu 2002).

SANParks did employ an effective and well managed project management regime and was very specific in terms of the products they wanted (Knight 2004 pers. comm.). They were clearly passionate about the establishment of the park, which probably manifested in their approach to their project management function as a contribution towards realising the gAENP vision. It also ensured efficiency in terms of time and resources (KPI 5.2). However, the lead SEA consultant (who was also responsible for the social specialist studies) indicated that communication with the conservation plan- ners was inadequate and left some room for improvement (Griffith 2004 pers. comm.).

Although the SEA did make provision for a review period of 28 days for IAPs, environmental authorities (national and provincial) had not commented on the SEA by the time of the review in July 2004 (Avis 2004 pers. comm.). The consultant specifically expressed the need to tidy up the review process (Avis 2004 pers. comm.). Moreover, SANParks never formally adopted the SEA and confirmed that it only serves as an informal information document (Knight 2004 pers. comm.) (KPI 4.2). Also, the SEA was never given closure through formal commitment from SANParks to implement the proposals. Two other factors worried the consultants, namely the fact that the SEA was conducted outside a formal regulatory framework as well as the status of SANParks as a statutory body of the national Department of Environmental Affairs and Tourism (DEAT), effectively positioning them as referee and player. The latter prompted the consultant to write a formal letter on 1 August 2002 to DEAT asking “... could you please explain how the decision making process would work. In this instance National DEAT is both referee and player, and IAPs have been concerned that all decisions would fall in favour of SANParks" and "Could you therefore map out for us the regulatory framework within which decisions regarding the establishment of the gAENP will be made."

No formal reply was received (Avis 2004 pers. comm.). Not surprising, some key role players expressed their doubts on whether SANParks would actually implement the proposals of the SEA. However, from the following sections it is clear that SANParks, in the end, did indeed use and implement some of the SEA proposals.

\section{- $\quad$ SEA methodology component}

The methodology review results show that the SEA failed to conform to five indicators, partly conformed to eight, and conformed to four of the 17 indicators. This section presents the quality performance of the method- 
ology with specific reference to KPIs 6.1, $6.2,6.3,7.1,7.2,7.3,8.1,8.3,8.4,9.1$ and 10.1 .

The methodology of the SEA was primarily designed to deliver the terms of reference (TOR). A formal screening method was not applied (KPI 6.1) and SANParks, in consultation with DEAT, drafted the TOR. The first and most significant aspect of the TOR was that it did not include a requirement to specifically assess anything (KPI 6.3). Rather it specified that the SEA should essentially integrate the specialist information in order to identify opportunities and constraints and describe the socio-economic and biophysical implications of establishing the gAENP, and finally, make proposals for the way forward (CES 2002). This was exactly what the SEA did. So it could almost be considered more of a feasibility study on the desirability of the park expansion than an assessment.

As part of the situational analysis, a total of 17 specialist studies were conducted, covering biophysical, social, economic and institutional aspects (KPI 7.2). It was explained that the SEA followed a nested approach where the biophysical and social assessments focussed on the planning domain and the legal, economic and institutional assessments focussed more broadly, looking at interactions within the region. Each specialist study had its own TOR and applied its own methodology, which ranged from detailed GIS analysis (for the conservation planning) to simple desktop studies and descriptions (for the economic and institutional studies). The budgets for each study also varied greatly, with the majority of funds allocated towards conservation planning. All this resulted in different levels of detail and formats, which made integration of specialist studies exceedingly difficult (KPI 7.1). For example, the conservation plan (C-plan) classified detailed land parcels according to irreplaceability from where priority expansion areas were identified (CSIR 2001b). The social data relied on a representative sample, consisting of 16 farms spread throughout the planning domain (Connor 2002). SANParks confirmed that the aim to link the social and biophysical data at the same geographic scale and level of detail, by means of GIS, was never achieved (Gordon 2004 pers. comm.; Knight 2004). This illustrates that the broadbrush social analysis could not purposefully influence the specific land purchases envisaged by the C-plan.

The boundary of the study area was also a key aspect influencing methodology. The boundaries of the gAENP initiative were determined based on certain conservation and development goals even before the SEA was initiated. The SEA study area was subsequently referred to as a planning domain wherein, crucially, the boundaries were not fixed, primarily because SANParks argued that the future extent of the park would be continuously influenced by new information and the development of relationships with private landowners (CES 2002). The flexible nature of the boundaries caused various problems for data gathering and public participation respectively (KPI 7.1). This was because the planning domain was largely determined based on biodiversity significance and subsequently did not correspond to administrative boundaries. Since most existing economic and social data were linked to municipal or district boundaries it was at times difficult to match data with the boundaries of the planning domain (Geach 2002; Timmermans \& Sisitka 2002). The public participation process suffered because IAPs could not gauge the influence of the exact extent of the park on them. It also created feelings of mistrust and uncertainty (Wren \& Msutu 2002). It is understandable that for private landowners it was imperative for the park to indicate exact boundaries so that they could assess the potential impact on their livelihoods.

As part of the situation analysis, a key deliverable of the SEA was the identification of opportunities and constraints for the gAENP proposal (KPI 7.3). Afterwards SANParks described the opportunities and constraints approach as amorphous and not very rigorous (Knight 2004 pers. comm.). On the other hand the consultant considered it a valuable and beneficial approach but pointed out one specific limitation. What was an opportunity 
for one alternative (such as conservation) was a constraint for the other (such as agriculture) and vice versa, which implied that the interpretation differed depending on the proponent (Avis 2004 pers. comm.). For instance, the lower agricultural potential of the Zuurberg area provides an opportunity for conservation and a threat to agriculture. Similarly, the high agricultural potential of the Alexandria area presents an opportunity for agriculture and a threat to conservation. The latter was even more significant in light of the fact that only one land-use alternative, namely conservation, was considered and other alternatives such as improving the status of agriculture were not. The consultant highlighted the failure to pursue any alternatives (for the area) other than conservation, as a significant limitation of the SEA (CES 2002). However, it was argued by SANParks that other alternatives were not forthcoming due to the fact that they were not considered viable and that conservation was the only alternative worth pursuing (CES 2002; World Bank 2002). There was also no proponent for other alternatives or funds to investigate their viability. Although only one overriding land-use alternative was put forward, various development scenarios (in terms of tourism products and game farming) as well as management arrangements (in terms of contractual parks) were considered as part of the specialist studies (Davies 2002; Timmermans \& Sisitka 2002). These were referred to as incremental alternatives (CES 2002).

Although no specific scoping phase could be distinguished, issues were scoped based on public participation and specialist studies (CES 2002; Wren \& Msutu 2002) (KPI 8.1). However, these issues were not prioritised or weighted in terms of relevant significance (KPI 8.3). Since the SEA ended up with a relatively small number of key issues, prioritisation was probably not that critical, although it would have been especially helpful in the implementation of the SEA proposals. However, the consultant indicated that an attempt was made to prioritise through a scoring exercise during a specialist workshop but that it was abandoned due to time constraints (Griffith 2004 pers. comm.). The contribution that public participation made to the identification of key issues for the area can hardly be overstated (KPI 8.4). It is significant to note that the majority of strategic issues raised through the specialist studies also seemed to have been captured during the participation process, which might be an indication that public participation could serve as a valuable substitute where specialist inputs are not available or affordable.

The fundamental methodological limitation of the SEA, which negated the possibility of actually conducting an assessment, was that it failed to set objectives, targets and indicators (which could have formed part of a sustainability framework) and nobody seemed to know how to address this limitation (KPI 9.1). This was especially true for the social aspects, but less so for the biophysical because conservation targets were set for the terrestrial environment (CSIR 2002). However, since overall targets and indicators were not set it was difficult to determine the sustainability and viability of, for instance, the conservation targets against social targets. The lack of targets and indicators also meant that no monitoring arrangements were put in place (KPI 10.1). So, SANParks highlighted that there was a definite need for an implementation phase to bridge the gap between planning and implementation (Gordon 2004 pers. comm.). For instance, there was no direct interaction between the lead SEA consultant and the park management, which suggests that the integration of the SEA with actual park management was limited and that the new integrated environmental management system (IEMS) for the park was designed separately from the SEA.

\section{SEA documentation component}

The SEA documentation conformed to six indicators, partly conformed to five, and did not conform to four of the 15 indicators. This section presents the performance of the SEA with specific reference to KPIs 11.2, 11.3, $12.2,13.1,13.3,14.1,14.3$ and 14.4. 
The SEA documentation consisted of 17 specialist study reports, the results of which were integrated into a single SEA report (CES 2002), that described opportunities and constraints and made proposals for the way forward. An executive summary was also included (KPI 14.3). Not surprising, the areas of partial and non-conformance could be related back to limitations also reflected in the process and methodology components. For instance, the SEA process did include a formal participation process, which was well recorded and thus those involved in consultation and participation were clearly described and inputs received from the public were incorporated in the report (KPI 4.4). Also the SEA did not consider any other fundamental land-use alternative than conservation, thus no alternatives were described in the documentation (KPI 13.3).

The review results show that the context of the SEA was not well described, apart from those involved with consultation and participation (KPI 11.2). The reader could not identify linkages between the SEA and other decision making processes. In addition, more importantly, the actual SEA process was not described (in relation to the gAENP development process) (KPI 11.3). The lack of objectives, targets and indicators and clear methodologies for screening, scoping and assessment resulted in the lack of descriptions of the state of the environment (KPI 12.2) and assessment methodologies (KPI 13.1). However, the SEA did communicate its results well. The documents were logically arranged, well referenced and the inputs received from the public were clearly incorporated (KPI 14.1). This might also be one of the advantages of having a formal public participation process which ensures that information is presented in a user-friendly format. The availability of the SEA documentation on the internet was also a definite advantage of the SEA. It can be concluded that the documentation can only provide what the SEA process and methodology were designed to deliver.

\section{Output effectiveness components}

The review results suggest an average to good effectiveness performance and show that the SEA did deliver on the TOR and partly influenced policy and decision making. The following sections discuss the direct and indirect outputs of the SEA.

\section{Direct outputs component}

The SEA recommendations highlighted gaps in information and policy as well as shortcomings in participation and communication, which needed to be addressed as part of the way forward. During interviews with SANParks it was confirmed that the majority of these information gaps have been addressed since the completion of the SEA, and that the shortcomings in consultation and participation were also addressed through the restructuring of the Addo Planning Forum (Knight 2004 pers. comm.). In terms of policy, the SEA directly influenced the decision by SANParks to draft a Resettlement Policy as well as a Land Acquisition Policy (KPI 15.1).

Most significantly, the SEA influenced decisions relating to land acquisition (KPI 17.1). The best example was the decision by SANParks to abandon the prospect of purchasing land in the coastal dairy farming region, especially around Alexandria (Avis 2004 pers. comm.; Knight 2004). This region is ideally suited to dairy farming and serves as one of the most productive dairy regions in the country. The SEA public participation process pointed out that there were serious public objections against expansion of the park in this area (Wren \& Msutu 2002). Unfortunately, isolated cases were even found where farmers cleared indigenous forest to influence the biodiversity value of their land in an effort to make it unattractive for expropriation. The decision by SANParks to exclude this area from their short to mediumterm land acquisitions, took a lot of heat off the project (Knight 2004 pers. comm.).

But, the SEA also provided information to SANParks on the biodiversity, social and economic aspects in the area. It showed 
that land prices in some areas were high and rehabilitation would be time consuming and expensive, giving it a low priority from a conservation planning perspective. Also, and probably more importantly, the financial scenarios indicated that the income generated through tourism and game farming (R103/ ha) could not compete with that generated through dairy farming (R177/ha) (Antrobus 2002). The SEA also highlighted the potential impact the park may have on the Kommadagga, Glenconner and Kleinpoort areas which fall within some of the highest mohair producing areas in the world. Although land purchase proposals in this area have not been abandoned by SANParks, they decided to investigate in more detail the potential impact of the park on mohair production.

The question whether the SEA influenced environmental quality was difficult to gauge since no monitoring (social or biophysical) had been conducted. However, the perception was that more land under conservation, due to the gAENP initiative, implies improved environmental quality from a conservation perspective (Knight 2004 pers. comm.) (KPI 18.1). However, SANParks confirmed that, in retrospect, failure to address the social issues could have jeopardised the entire project (Gordon 2004 pers. comm.). What remained unresolved was the need to formulate targets and indicators for the social and biophysical environments to gauge environmental quality from a sustainability, as well as conservation, perspective. The use of environmental reporting was being considered by SANParks and might form part of their management system in future (Gordon 2004 pers. comm.; Knight 2004).

\section{- $\quad$ Indirect outputs component}

The most significant indirect output of the SEA was a raised awareness by SANParks towards social issues related to conservation. SANParks admitted that they were surprised about the social aspects and initially did not fully anticipate them (Knight 2004 pers. comm.). This state of affairs might also reflect a general tendency amongst conservationists to underestimate social issues in decision making. The fact that SANParks has since improved their data and policy on the social environment as well as communication channels with communities is testimony that they are serious about the social aspect and intend to integrate them fully with their IEMS.

According to SANParks the SEA also raised awareness of the gAENP initiative with local authorities and ways of integrating the SEA with local integrated development plans and spatial development frameworks were being investigated at the time (Gordon 2004 pers. comm.) (KPI 15.2). However, this remained a difficult task since local authorities are under severe resource constraints. Moreover, nobody seems to know whose responsibility it was to ensure the integration of the gAENP initiative with local authority decision making. Finally, it was also confirmed that EIA consultants have contacted SANParks to obtain the SEA information to assist in their EIAs in the area (Gordon 2004 pers. comm.). Although this cannot be considered a formal tiering arrangement, it at least indicates awareness of the SEA and that it was being considered as a source of background information (KPI 17.3).

To address the gaps in information relating to tourism, SANParks initiated a study on the impact of the gAENP on provincial economy. With regard to the lack of information on farm occupancy, a detailed farm survey has also been conducted and a farm register established (Gordon 2004 pers. comm.). Finally, various information gaps were indicated in terms of the marine environment. Initially, SANParks hoped to use the same management model for the terrestrial and marine components of the park but through the SEA realised that this would not be feasible. Subsequently a study to address information gaps on the marine environment has also been initiated (Knight 2004 pers. comm.).

\section{Conclusion}

The SEA for the gAENP proved particularly challenging due to the extent and diversity of the planning domain, the national and international significance of the initiative, 
diverse interests in the region, and the fact that ultimately it involved the contentious issue of land ownership. However, notwithstanding some limitations it integrated well with strategic decision making and involved a comprehensive public participation process. Ultimately, the research results showed that the SEA achieved an average to good effectiveness performance where it influenced key controversial decisions on park expansion.

The main lessons learned for application of SEA to future park expansion initiatives are:

- Firstly, to be effective, SEA needs to be initiated as early as possible. Because of the lack of integration with early conceptualisation the gAENP SEA was limited, by its very design, to purposefully influence important strategic decisions concerning the vision and strategic objectives. Moreover, its restrictive mandate (as reflected in the TOR) and lack of legal framework further hampered implementation. It is evident that SEA should ideally be conducted within a clearly defined regulatory and institutional framework to ensure that outcomes are considered and incorporated into decision making.

- Secondly, from an environmental assessment point of view, the main impacts to consider relate to the social domain. As illustrated by the case study, the expansion of a conservation area mainly complements and improves the bio-physical environment, but could imply potentially significant social impacts. Thus, although understanding the bio-physical environment is critically important from a park management and planning perspective, more prominence towards dealing with social issues are required from an environmental impact assessment perspective. A balance needs to be struck between conservation targets and socio-economic development priorities.

- Thirdly, setting and communicating spatial boundaries is a key consideration for the expansion of conservation areas. The case study has shown that it is very difficult to engage with IAPs if park expansion boundaries are not clarified up front and well communicated to those affected. Vague boundaries create mistrust within the communities and hampers ultimate buy-in. Rather, conservation targets and boundaries need to be communicated through a consultative process exploring alternative scenarios.

- Finally, dealing with scale is important from a data gathering and ultimately data integration perspective. It is extremely difficult to consider trade-offs between bio-physical and social impacts if the scale and level of detail of the data differs. Thus special consideration in the design of the SEA methodology needs to be given towards aligning the different specialist studies. This could be addressed through the formulation of the TORs and assigning comparable time and resources to different specialist inputs.

Based on the research results it can thus be concluded that SEA is a useful tool to assists strategic decision making for park expansion. To take the debate forward and further explore the potential of SEA as a decision support tool it is proposed that comparative case study research be conducted for a number of case studies. Existing research and anecdotal evidence suggests that more than a dozen SEAs have been conducted in the conservation sector. Such multiple case study research would allow for the identification of communalities and patterns between cases, leading towards increased generalisation and the potential to benchmark best practice.

\section{Acknowledgements}

The contribution of all the various interviewees are gratefully acknowledged, with special reference to Dr Michael Knight and Jill Gordon from SANParks, Dr Ted Avis and Michelle Griffith from 'Coastal and Environmental Services' as well as Sandy Wren from 'Sandy and Mazizi Consulting'. Valuable inputs were also received from Dr Carys Jones, University of Manchester and Dr Stephen Jay, Sheffield Hallam University. The author would like to thank the external reviewers for their insightful comments which added value to the revised version. 
Finally, appreciation to the Commonwealth Scholarship Commission for their financial support without which, the research would not have been possible.

\section{References}

ANTRobus, G. 2002. Strategic Environmental Assessment of the greater Addo Elephant National Park-Specialist report no.10-Income from livestock farming. Grahamstown: Rhodes University.

Brownlie, S., C, De Villiers, A. Driver, N. Job, A. VON HASE \& K. MAZE. 2005. Systematic conservation planning in the Cape Floristic Region and Succulent Karoo, South Africa: enabling sound spatial planning and improved environmental assessment. Journal of Environmental Assessment, Policy and Management 7(2): 201-228

Cashmore, M., R. Gwilliam, R. Morgan, D. CobB, D. \& A. Bond. 2004. The interminable issue of effectiveness: substantive purposes, outcomes and research challenges in the advancement of environmental impact assessment theory. Impact Assessment and Project Appraisal 22(4): 295-310

Coastal and Environmental Services (CES). 2002. Strategic Environmental Assessment of the greater Addo Elephant National Park. Grahamstown: Coastal and Environmental Services.

ConNor, T. 2002. Strategic Environmental Assessment of the greater Addo Elephant National Park-Specialist report No. 6-Social Assessment. Port Elizabeth: South African National Parks.

COUNCIL FOR SCIENTIFIC AND Industrial Research (CSIR). 1996. Strategic Environmental Assessment (SEA) - a primer. Stellenbosch: Council for Scientific and Industrial Research.

COUNCIL FOR SCIENTIFIC AND INDUSTRIAL RESEARCH (CSIR). 2001a. Final report on the proposed marine protected area for the greater Addo Elephant National Park aquatic conservation planning. Stellenbosch: Council for Scientific and Industrial Research.

COUNCIL FOR SCIENTIFIC AND INDUSTRIAL RESEARCH (CSIR). 2001b. Preliminary survey and desktop approach to conservation planning of freshwater ecosystems in the greater Addo Elephant National Park. Stellenbosch: Council for Scientific and Industrial Research.

COUNCIL FOR SCIENTIFIC AND INDUSTRIAL RESEARCH (CSIR). 2002. Final Report: Conservation planning framework for the greater Addo Elephant National Park. Stellenbosch: Council for Scientific and Industrial Research.

Dalal-Clayton, B. And Sadler, B. 2005. Strategic Environmental Assessment: a sourcebook and reference guide to international experience. London: Earthscan.

DaviES, R. 2002. Strategic Environmental Assessment of the greater Addo Elephant National Park-Specialist report no. 11-Ecotourism scenarios. Port Elizabeth: South African National Parks.

DEPARTMENT OF ENVIRONMENTAL AFFAIRS AND TOURISM (DEAT). 2000. Strategic Environmental Assessment (SEA) in South Africa: Guideline Document. Pretoria: Department of Environmental Affairs and Tourism.

DEPARTMENT OF ENVIRONMENTAL AfFaIRS AND TOURISM (DEAT). 2004a. National Biodiversity Strategy and Action Plan. Pretoria: Department of Environmental Affairs and Tourism.

DEPARTMENT OF ENVIRONMENTAL AFFAIRS AND TOURISM (DEAT). 2004b. Strategic Environmental Assessment, Integrated Environmental Management, Information Series 10. Pretoria: Department of Environmental Affairs and Tourism.

GEACH, B. 2002. Strategic Environmental Assessment of the greater Addo Elephant Park-Specialist report No.9-Economic activities in the planning domain. Johannesburg: South African National Parks.

Glazewski, J. 2005. Environmental Law in South Africa. Cape Town: Butterworths.

INTERNATIONAL ASSOCIATION FOR IMPACT ASSESSMENT (IAIA). 2002. Strategic Environmental Assessment Performance Criteria. IAIA Special Publication Series No.1, International Association for Impact Assessment: Fargo.

Jones, C., M. Baker, J. Carter, S. Jay, M. Short \& C. Wood. 2005. Strategic Environmental Assessment and land use planning: an international evaluation. London: Earthscan.

Kerley, G. \& A. Boshoff. 1997. A proposal for a greater Addo National Park - a regional and national conservation and development opportunity. Terrestrial Ecology Research Unit, University of Port Elizabeth. Port Elizabeth.

Kolmoff, A. \& R. Slootweg. 2005. Biodiversity in SEA for spatial plans - experiences from the Netherlands. Journal of Environmental Assessment, Policy and Management 7(2): 267-286

LAWRENCE, D. 1997. Quality and effectiveness of environmental impact assessments: lessons and insights from ten assessments in Canada. Project Appraisal 12(4): 219-232

Lochner, P., A. Weaver, C. Gelderblom, P. RaEWyn, T. SANDWith \& S. Fowkes. 2003. Aligning the diverse: the development of a biodiversity conservation strategy for the Cape Floristic Region. Biological Conservation 112: 29-43

MARSDEN, S. 1998. Importance of context in measuring the effectiveness of strategic environmen- 
tal assessment. Impact Assessment and Project Appraisal 16(4): 255-266

Miles, M. \& A. Huberman. 1994. An expanded source book: qualitative data analysis. London: Sage.

National Botanical Institute (NBI). 2002. Mainstreaming biodiversity at the bioregional scale. Parallel workshop event at the World Summit on Sustainable Development, August 2002. National Botanical Institute: Johannesburg.

Owens, S., T. RAYNER \& O. BinA. 2004. New agendas for appraisal: reflections on theory, practice, and research. Environment and Planning 36: 1943-1959

PARTIDARIO, M. \& J. ARTS. 2005. Exploring the concept of SEA follow-up. Impact Assessment and Project Appraisal 23(3): 246-257

RETIEF, F. 2005 Quality and effectiveness of strategic environmental assessment (SEA) in South Africa. Ph.D. thesis, School of Environment and Development. University of Manchester, Manchester.

Rossouw, N., M. Audouin, P. Lochner, S. HeathER-Clark, \& K. Wiseman. 2000. Development of Strategic Environmental Assessment in South Africa. Impact Assessment and Project Appraisal 18(3): 217-223

Rossouw, N. \& K. Wiseman. 2004. Learning from the implementation of environmental public policy instruments after the first ten years of democracy in South Africa. Impact Assessment and Project Appraisal 22(2): 131-140

SADLER, B. 1996. International study of the effectiveness of environmental assessment-Final Report. Environmental Assessment in a changing world: Evaluating practice to improve performance. Ottawa: International Association for Impact Assessment and the Canadian Environmental Assessment Agency.

SAdLer, B. 2004. On evaluating the success of EIA and SEA. Pp. 248-285. In: MorrisOn-SAUNDERS, M. \& J. ARTS (eds.). Assessing impact: Handbook of EIA and SEA follow-up. London: Earthscan.

Schmidt, M., E. JoAo \& E. Albrecht. 2005. Implementing Strategic Environmental Assessment. New York: Springer.

Terrestrial And ECOlogy RESEARCH Unit (TERU). 1999. Report-greater Addo National ParkStakeholder Workshop, 23 February 1999. Terrestrial and Ecology Research Unit, University of Port Elizabeth. Port Elizabeth.

Therivel, R. \& P. MinAs. 2002. Ensuring effective sustainability appraisal. Impact Assessment and Project Appraisal 20(2): 81-91
Therivel, R. \& M. Partidario. 2000. The future of SEA. Pp. 271-280. In: Partidario, M. \& R. Clark (eds). Perspectives on Strategic Environmental Assessment. Boca Raton: CRC Press.

Thissen, W. 2000a. Criteria for the evaluation of SEA. Pp. 113-127. In: PARTIDARIO, M. \& R. Clark (eds). Perspectives on Strategic Environmental Assessment. Boca Raton: CRC Press.

Thissen, W. 2000b. Strategic environmental assessment at a crossroads. Impact Assessment and Project Appraisal 18(3): 174-176

Timmermans, H. \& L. SisitKA. 2002. Strategic Environmental Assessment of the greater Addo Elephant National Park-Specialist report no. 14-Institutional review. Grahamstown: Institute of Social and Economic Research, Rhodes University.

ToDD, S. 2001. Measuring effectiveness of environmental dispute settlement efforts. Environmental Impact Assessment Review 21: 97-110

Treweek, J., R. Therivel, S. Thompson \& M. SLATER. 2005. Principles for the use of strategic environmental assessment as a tool for promoting the conservation and sustainable use of biodiversity. Journal of Environmental Assessment, Policy and Management 7(2): 173-199

Verheem, R. \& J. TonK. 2000. Strategic Environmental Assessment: One concept multiple forms. Impact Assessment and Project Appraisal 18: $177-182$

World BANK. 2002. Project Brief-Funding for the establishment of the greater Addo Elephant National Park. Johannesburg: World Bank.

World Conservation Monitoring CEnTre. 1992. Global Biodiversity: Status of the Earth's Living Resources. London: Chapman and Hall.

World Conservation Monitoring Centre. 2002. World Atlas of Biodiversity-Earth's living resources in the 21st century. California: University of California Press.

Wren, S. \& M. Msutu. 2002. Strategic Environmental Assessment of the greater Addo Elephant National Park-Specialist study No 5-Public participation. Port Elizabeth: Sandi \& Mazizi Consulting.

WynBerg, R. 2002. A decade of biodiversity conservation and use in South Africa: tracking progress from the Rio Earth Summit to the Johannesburg World Summit on Sustainable Development. South African Journal of Science 98: 233-243

YIN, R. 2003. Case study research: Design and methods-Applied social research methods series. Volume 5. London: Sage. 